\title{
Motor-sparing spinal anesthesia to allow active balancing during total knee arthroplasty
}

\author{
R. Marks, P. Meere, G. Cuff, R. Cuevas, A. Atchabahian \\ NYU School of Medicine - New York (United States)
}

\begin{abstract}
Background and Goal of Study: Successful total knee replacement (TKA) is dependent, among other factors, on balancing peak load at the medial and lateral tibiofemoral joint interfaces. This can be achieved with the assistance of a sterile sensor system intra-operatively. On the request of one surgeon at our institution, we explored the feasibility and safety of surgical spinal anesthesia with limited motor blockade.
\end{abstract}

Materials and Methods: 25 patients were enrolled in an IRBapproved non-randomized pilot study. Inclusion criteria included patients at least 50 years of age and willing to participate in preand postoperative surveys. For spinal anesthesia, a solution consisting of $1 \mathrm{~mL}$ of $5 \mathrm{mg} / \mathrm{mL}$ isobaric bupivacaine in combination with $1.5 \mathrm{~mL}$ sterile saline solution containing 7.5 mcg of sufentanil was administered. During the surgery, after components were cemented, patients were briefly awakened by interrupting propofol sedation and asked to move their leg in order to measure pressure balance. If an imbalance was noted, the surgeon would make any needed adjustments intraoperatively.
Results: During the intraoperative wake-up test, 15 patients successfully flexed and extended at the knee on command, while 10 were too weak for meaningful testing. As we reduced the local anesthetic volume to $0.8 \mathrm{~mL}$ in patients shorter than $160 \mathrm{~cm}$, that issue was eliminated. One patient had neutral recollection of the test on follow up. No patient had pain or other side effect.

Discussion: Two to $3 \mathrm{~mL}$ of a long-acting local anesthetic such as $0.5 \%$ bupivacaine is typically adequate for surgical anesthesia for TKA; however, patients will also exhibit motor weakness. A spinal anesthetic using sufentanil in combination with low-dose local anesthetic appears feasible and safe to provide surgical anesthesia for TKA. By performing a motorsparing spinal anesthetic with an intraoperative wake up test, we can allow surgeons to test active pressure balance to improve the accuracy of the pressure balancing technique. A randomized study is in preparation to determine whether long-term surgical result is improved by optimizing knee balance intraoperatively.

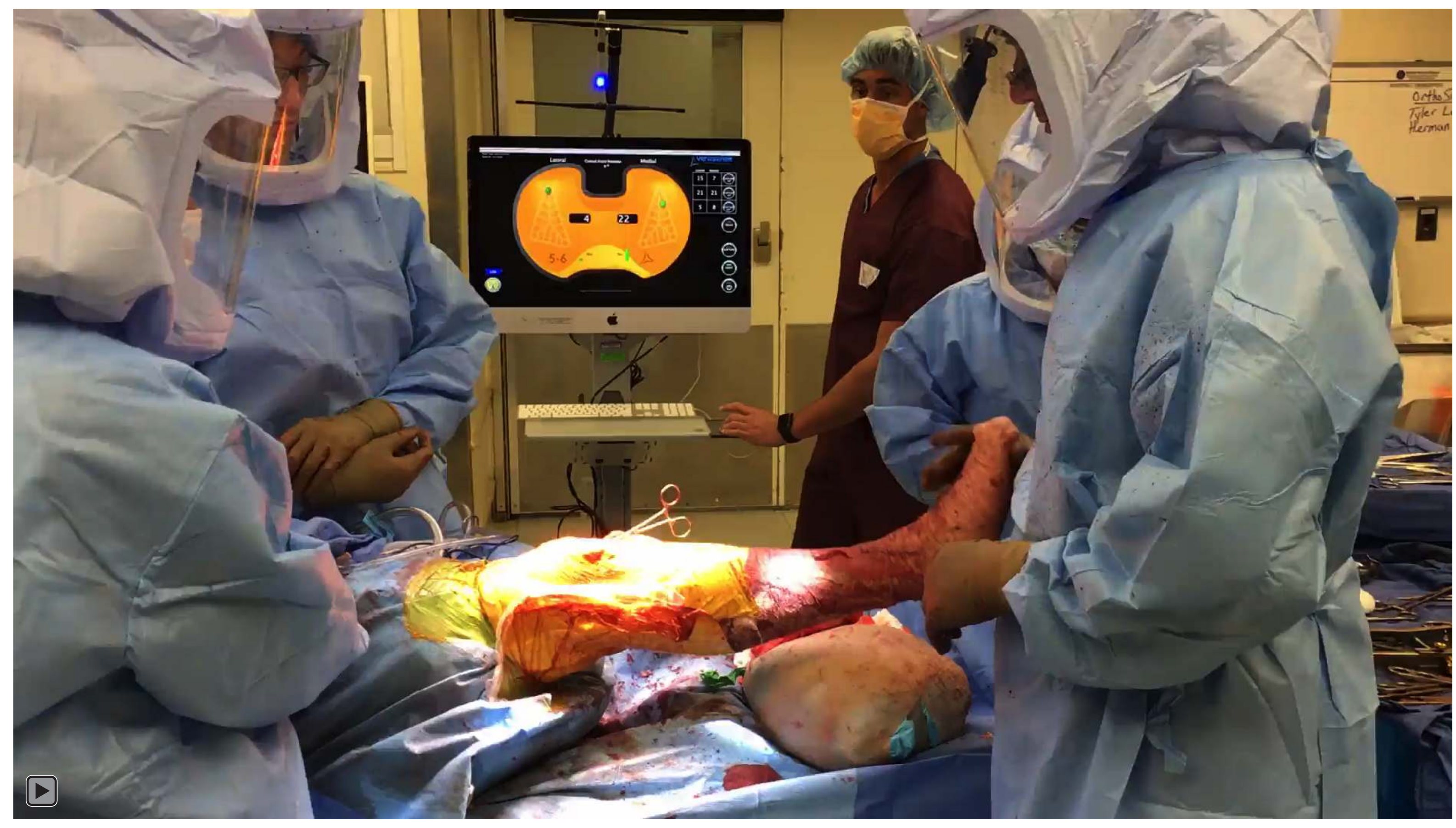

References

- Mihalko WM, Whiteside LA, Krackow KA. Comparison of ligament- balancing techniques during total knee arthroplasty. J Bone Jt Surg. 2003;85(4):132-5.

- Eriksson SL, Blomberg I, Olofsson C. Single-shot intrathecal sufentanil with bupivacaine in late labour - analgesic quality and obstetric outcome. Eur J Obstet Gynecol Reprod Biol. 2003 Oct 10;110(2):131-5.

- Olofsson C, Nygårds EB, Bjersten AB, Hessling A. Low-dose bupivacaine with sufentanil prevents hypotension after spinal anesthesia for hip repair in elderly patients. Acta Anaesthesiol Scand. 2004 Nov;48(10):1240-4. 